\title{
A proposta da Base Nacional Comum Curricular para o ensino de Arte
}

\author{
The proposal of the Common Curricular National Base for teaching Arts \\ La propuesta de la Base Nacional Común del Curriculum para la enseñanza de Arte
}

\author{
Denise Andrade de Freitas Martins ${ }^{1}$; Maria Aparecida Augusto Satto Vilela ${ }^{2}$ \\ UNIVERSIDAdE EST ADUAL DE MINAS GERAIS, UEMG, ITUIUTABA-MG, BraSIL \\ Universidade Federal de Uberlândia, UFU, Pontal-MG, Brasil
}

\begin{abstract}
RESUMO
Contextualizamos brevemente o processo de discussão, elaboração, promulgação e homologação da BNCC, seguindo-se à sua problematização, com ênfase no ensino de arte na Educação Infantil e Ensino Fundamental, na tentativa de levantar os limites e as potencialidades da BNCC. Entendemos que este documento é o ponto final do percurso, que é o currículo (o quê, porquê, quando e como ensinar), dependendo de quem o realiza in loco, de modo a ser capaz de ação-reflexão-ação, ou seja, a práxis enquanto atividade de cada pessoa envolvida na promoção de uma educação escolar brasileira transformadora e libertadora.
\end{abstract}

Palavras-chave: Base Nacional Comum Curricular. Ensino de Arte. Educação Infantil. Ensino Fundamental.

\begin{abstract}
We have briefly contextualized the discussion, elaboration, promulgation and homologation of Common Curricular National Base, following its problematic, emphasizing the teaching of arts in Children's Education and Elementary School, when trying to raise the bar and potential of Common Curricular National Base. We understand that this document is the final stop of this route, which is the curriculum (what, why, when and how to teach), depending on who performs it in loco, so as to being capable of acting-reflecting-acting, that is, the practice while activity of each person involved in the promotion of a transforming and freeing Brazilian school education.
\end{abstract}

Keywords: Common Curricular National Base. Arts Teaching. Children's Education. Elementary School.

\section{RESUMEN}

Contextualizamos brevemente el proceso de discusión, elaboración, promulgación y homologación de la Base Nacional Común del Curriculum, luego de su problematización, con énfasis en la enseñanza del arte en la enseñanza de niños y en la escuela primaria, en un intento de elevar los límites y las potencialidades de la Base Nacional Común del Curriculum. Entendemos que este documento es el punto final del recorrido, que es el plan de estudios (qué, por qué, cuándo y cómo enseñar), dependiendo de quién lo hace in loco, con el fin de ser capaz de acción-reflexión-acción, esto es, La praxis mientras actividad de cada persona involucrada en la promoción de una educación escolar brasileña transformadora y liberadora.

Palabras clave: Base Nacional Común del Curriculum. Educación Artística. Enseñanza de Niños. Escuela Primaria.

\footnotetext{
${ }^{1}$ Docente da UEMG, unidade Ituiutaba. E-mail: deniseafmartins@ outlook.com

${ }^{2}$ Docente da UFU, Câmpus Pontal. E-mail: cidasatto@hotmail.com
} 


\section{INTRODUÇÃOO}

Tendo em vista a homologação da Base Nacional Comum Curricular (BNCC) em 2018, faz-se necessário discutir, analisar e pensar esse documento na perspectiva de sua implementação. Pensando-se na grandeza territorial e diversidade cultural brasileiras, são muitos os desafios que se colocam à frente. No entanto, cabe a cada um/a de nós a tomada pelas mãos dessa tarefa, sem perder de vista a necessidade de intersubjetivação e problematização de tudo aquilo que perpassa a educação escolar no Brasil, dentre metas, desafios, necessidades e limitações.

Desse modo, neste artigo, nos propusemos a pensar e discutir a BNCC, traçando, mesmo que brevemente, sua trajetória e processo de implantação, com ênfase ao ensino de arte na Educação Infantil e nos anos iniciais do Ensino Fundamental, assim como compartilhar experiências, em busca de suscitar reflexões que contribuam para o exercício crítico e cidadão de ser professor e professora no Brasil, compromisso de todo/a profissional que acredita na força e potência da Educação.

Para tal, contextualizamos brevemente o processo de discussão, elaboração, promulgação e homologação da BNCC, seguindo-se à sua problematização, com ênfase no ensino de arte na Educação Infantil e Ensino Fundamental. Concluímos a discussão com a reflexão sobre os limites e as potencialidades da BNCC.

\section{A Base NaCional Comum Curricular (BNCC)}

A BNCC é o documento que hoje normatiza o currículo da educação brasileira. Nesse sentido, entendemos ser necessário, inicialmente, reconstruir a trajetória de sua elaboração, aprovação e homologação. Na Constituição Federal de 1988, a qual assegura uma Educação Básica de qualidade e de direito para todos/as, estão fixados os conteúdos mínimos, em seu artigo 210, parágrafos $1^{\circ}$ e $2^{\circ}$ (BRASIL, 1988). Posteriormente, e na sequência, a Lei de Diretrizes e Bases - LDB, Lei 9394/1996, em seu artigo 26, fixou que os currículos (ensino fundamental e médio) teriam uma base nacional comum, a ser complementada pelos sistemas de ensino (secretarias, escolas, instituições) (BRASIL, 1996). Esse texto foi alterado, posteriormente, pela Lei 12796/2013, que incluiu a Educação Infantil, para as crianças até os cinco anos (BRASIL, 2013a).

Destacamos ainda que, no período de 1997 a 2000, foram implementados pelo Ministério da Educação (MEC), os Referenciais Curriculares Nacionais da Educação Infantil (RCNEI) (BRASIL, 1997) e os Parâmetros Curriculares Nacionais (PCN) (BRASIL, 1997) para o ensino fundamental e médio, na tentativa de orientar a elaboração dos currículos nos diferentes âmbitos (estadual e municipal) e nas diversas etapas de ensino. Na sequência, o Plano Nacional de Educação (PNE), com vigência de 2001-2010, garantia, além das condições para acesso à escola, a permanência nela, valorizando um currículo que, na educação infantil, contribuísse para a construção da inteligência da criança; e, no ensino fundamental também garantisse a interdisciplinaridade (BRASIL 2001). Além do PNE, outros dispositivos passaram a orientar as políticas públicas de educação no Brasil, entre eles as avaliações do Sistema de Avaliação da Educação Básica (SAEB), da Prova Brasil e do Exame Nacional do Ensino Médio (ENEM), definidas como constitutivas do Sistema de Avaliação da Qualidade da Oferta de Cursos no País.

A promulgação da Emenda Constitucional no 59/2009, dentre suas medidas, assegurou, no artigo 208, inciso I, a “[...] educação básica obrigatória e gratuita dos 4 
(quatro) aos 17 (dezessete) anos de idade, [...] inclusive sua oferta gratuita para todos os que a ela não tiveram acesso na idade própria" (BRASIL, 2009). Em relação à primeira etapa da educação básica, as Diretrizes Curriculares Nacionais para a Educação Infantil (BRASIL, 2010) estabeleceram as normas para a educação de crianças de 0 a 5 anos, com base nos princípios éticos, políticos e estéticos, orientando a educação infantil e constituindo, assim, os eixos do trabalho pedagógico, baseado na linguagem, em articulação com a ludicidade e a interação social.

Posteriormente, as Diretrizes Curriculares Nacionais da Educação Básica (2013b) destacaram a formação escolar como:

[...] alicerce indispensável e condição primeira para o exercício pleno da cidadania e o acesso aos direitos sociais, econômicos, civis e políticos. [...] deve proporcionar o desenvolvimento humano na sua plenitude, em condições de liberdade e dignidade, respeitando e valorizando as diferenças (BRASIL, 2013b, p. 4).

Esse documento configurou-se:

[...] em efetivo avanço na agenda educacional ao delinear as concepções político-pedagógicas para todas as etapas e modalidades da Educação Básica, em atendimento ao previsto na atual LDB, e contribuindo de fato para a implantação da nova estrutura de educação estabelecem a base nacional comum, [orientando] a organização, articulação, desenvolvimento e avaliação das propostas pedagógicas de todas as redes de ensino brasileiras (BRASIL, 2013b, p. 4).

Para elaboração das Diretrizes, participaram das discussões o Conselho Nacional de Educação (CNE), depois de ouvidos o Conselho Nacional de Secretários de Educação (CONSED) e a União Nacional dos Dirigentes Municipais de Educação (UNDIME) $^{3}$. De tal forma que estas foram acolhidas pelo CNE, cujas propostas foram apresentadas por diversos segmentos de movimentos sociais, articulados e engajados na perspectiva de uma educação para os diferentes níveis e modalidades de ensino, com ênfase na valorização do direito à diferença (MACEDO, 2018).

Muitos documentos legais para a educação nacional produzidos nas duas primeiras décadas do século XXI, alguns deles citados anteriormente, trataram de questões relacionadas à diversidade humana: classe social, gênero, raça, etnia, geração, evidenciando os grupos que fazem parte da vida social brasileira (pobres, mulheres, afrodescendentes, indígenas, pessoas com deficiência, populações do campo, pessoas de diferentes orientações sexuais, albergados e/ou em situação de rua, privados de liberdade). A convivência nessa diversidade, de modo a promover a inclusão, fundamentou-se pela ética, liberdade, justiça social, pluralidade cultural, solidariedade e sustentabilidade, em busca do desenvolvimento de cada pessoa, contribuindo para a formação de cidadãos/cidadãs conscientes de seus direitos e deveres, compromissados/as com a transformação social.

Apesar dos avanços legais apontados é preciso se discutir sobre a eficácia dos documentos (resoluções, portarias, decretos e similares) como prescrição de atividades ou normas, já que a educação de qualidade social deve ser conquista da sociedade brasileira, manifestada pelos movimentos sociais. São muitos os desafios, porque, mesmo que normatizados, os documentos legais para a educação nacional não resolveram os problemas em relação à qualidade do ensino, formação e melhor

\footnotetext{
${ }^{3}$ O projeto da BNCC contou em sua formulação com a intervenção da Fundação Lemann, com consultoria prestada pela Universidade de Stanford, nos Estados Unidos.
} 
remuneração dos/as professores/as, dentre outros, levando-se em consideração que não há uma previsão ou preparação antecipada daqueles/as que deverão implantá-las e implementá-las. É preciso a participação da sociedade, da escola em particular, professores/as e estudantes, pais, mães, familiares e funcionários/as nas reivindicações de uma escola pública que tenha qualidade de ensino. Nesse contexto, as instituições de ensino precisam estar mais abertas e menos míopes aos/às diferentes protagonistas dessa história.

No tocante à BNCC, mesmo em face de impedimentos à participação efetiva de órgãos e pessoas de todo o processo de discussão que compõe uma gestão democrática participativa, conforme previsto na $\mathrm{LDB}$, o quadro foi de sua aprovação pelo CNE e sua homologação pelo MEC, excluindo-se o Ensino Médio e as diferentes modalidades de ensino (Educação de Jovens e Adultos, Educação Quilombola, Educação Especial, Educação Ambiental, Educação para as Relações Étnico-Raciais e para o Ensino de História e Cultura Afro-Brasileira e Africana, Educação Escolar Indígena).

Destacamos inicialmente, que os trabalhos de elaboração da BNCC tiveram início no segundo semestre de 2015, por meio do mapeamento dos currículos propostos nos estados brasileiros por assessores e funcionários do MEC, o que contribuiu para a elaboração da primeira versão do documento no mesmo ano. A criação de um portal eletrônico possibilitou o levantamento das contribuições do público em geral que teve, em sua maioria, consenso quanto à proposta. Contudo, por orientação da Secretaria de Educação Básica, trabalhou-se principalmente com o dissenso, com as discordâncias ao documento. Além disso, pareceristas críticos consultados para as diferentes áreas do conhecimento curricular contribuíram com apontamentos à primeira versão que, comparadas com as considerações identificadas no portal, subsidiaram a reformulação do documento ${ }^{4}$. Ressaltamos ainda, a realização de encontros realizados com estudantes, docentes e outros profissionais da educação pelo grupo organizador da BNCC, constituindo-se como mais uma fonte de informação para a publicação do documento no início de 2016 (segunda versão) ${ }^{5}$ (VALLADARES et al., 2016).

Outra ação desenvolvida foi:

[...] um seminário específico, no qual membros das equipes de todos os componentes discutiram e propuseram eixos comuns para composição de objetivos por etapa. Dos grupos, foram destacados alguns membros, por etapas escolares, para compor grupos que cuidassem, mais detidamente, das transições por etapas. O resultado desse trabalho alterou a redação do documento da segunda versão da BNCC (VALLADARES et al., 2016, p. 11).

Após a apresentação da segunda versão, realizaram-se cinco consultas públicas, além das proposições de membros do Conselho Nacional de Educação. Contudo, estas não foram incorporadas à última proposta da BNCC (AGUIAR, 2018). A aprovação do documento não obteve consenso interno entre seus membros, ou seja, não houve unanimidade entre os/as conselheiros/as do CNE, órgão normativo de âmbito nacional, tendo em vista colocações favoráveis à necessidade de outros estudos e aprofundamento nas discussões, o que exigia mais tempo e maior participação dos diferentes setores das

\footnotetext{
${ }^{4} \mathrm{O}$ grupo de pareceristas foi composto por professores/as de diversas universidades.

5 "Uma recomendação geral, já posta desde a primeira versão, mas bastante enfatizada na segunda, foi o não direcionamento teórico-metodológico das proposições, limpando termos que claramente identificavam correntes de pensamento no componente curricular, de modo a garantir a pluralidade e a opção por parte das redes/escolas/ professores nos projetos pedagógicos, bem como na formação de professores. A principal fonte a ser citada seria o próprio documento das DCN" (VALLADARES et al., 2016, p. 10-11)
} 
instituições responsáveis e comunidade interessada. Tal situação aparenta relativa fragilidade, o que poderá gerar impactos na organização do trabalho a ser desenvolvido pelos sistemas de ensino e pelas escolas (MACEDO, 2018).

Nessa conjuntura, a BNCC foi homologada, apresentando-se como sendo um documento a serviço do mercado de trabalho, com uma visão pedagógica centrada na aprendizagem. De tal forma, podemos dizer que a base é uma palavra que reforça aquilo a que veio representar, e como nenhuma palavra dá conta de seu significado, é preciso instaurar o imperativo de sua repetição, para manter a própria invenção. Por isso, é preciso reiterar o que afirmou Macedo (2018, p. 31): "A base é a base”.

\section{MAS, O QUE É A BNCC?}

A BNCC é um documento de caráter normativo, o qual define um conjunto de aprendizagens consideradas essenciais para todos/as os/as estudantes brasileiros/as ao longo das etapas e modalidades de ensino, que compõem a Educação Básica, em consonância com o Plano Nacional de Educação (PNE) - 2014 a 2024 (BRASIL, 2014). Os princípios que regem esse documento são orientados pela ética, política e estética, com vistas à formação integral, democrática, justa e inclusiva, em atendimento à LDB (1996), fundamentando-se também, nas Diretrizes Curriculares Nacionais da Educação Básica (DCN), bem como nos quatro pilares da Educação: o aprender a conhecer, o aprender a ser, o aprender a fazer e o aprender a viver (MARSIGLIA et al., 2017).

Em consonância com os documentos citados, a BNCC entende por competência um conjunto de atitudes, valores, conhecimentos e habilidades voltados para as atuais e complexas demandas do cotidiano das pessoas, no exercício da cidadania e do trabalho. Assim, como competências gerais da Educação Básica o documento destaca:

1. Valorizar e utilizar os conhecimentos historicamente já construídos [...].

2. Exercitar a curiosidade intelectual [...].

3. Valorizar e fruir as diversas manifestações artísticas e culturais [...].

4. Utilizar diferentes linguagens - verbal [...], corporal, visual, sonora e digital [...].

5. Compreender, utilizar e criar tecnologias digitais de informação e comunicação de forma crítica, significativa, reflexiva e ética [...].

6. Valorizar a diversidade de saberes e vivências culturais [...].

7. Argumentar com base em fatos, dados e informações confiáveis [...].

8. Conhecer-se, apreciar-se e cuidar de sua saúde física e emocional, compreendendo-se na diversidade humana e reconhecendo suas emoções e as dos outros $[\ldots]$.

9. Exercitar a empatia, o diálogo, a resolução de conflitos e a cooperação [...]. 10. Agir pessoal e coletivamente com autonomia, responsabilidade, flexibilidade, resiliência e determinação [...] (BRASIL, 2018, p. 9-10).

Ressaltamos que o processo de formação (inicial e continuada) de professores/as no Brasil é também responsabilidade da União, como prevê a BNCC, o que implica uma revisão de políticas e implementação de ações, uma vez que sua implementação depende da ação dos/as docentes. Nesse sentido, é preciso pensar e discutir a respeito da eficácia e sucesso da Base, tendo em vista a vastidão do território brasileiro, a diversidade de seu povo e, acima de tudo, das experiências e conhecimentos já consolidados de uma infinidade de escolas e profissionais da educação. Quantas e quantas são as cenas do dia a dia, sejam nas creches, escolas, universidades, praças, igrejas ou ruas, "prenhes" de significado e as quais não percebemos? (CERTEAU, 2014). 
São inúmeras as práticas e teorias do cotidiano, da formação acadêmica, das metodologias e conteúdos aplicados, das políticas de governo, dos processos de gestão, das pesquisas em educação, da produção e usos das mídias e tecnologias, da criação e (re)criação em artes, das vivências nas cidades e nos campos, dentre outras. Em síntese, são inúmeros os saberes e fazeres na educação escolar.

Nesse sentido, a literatura existente e disponível (MARSIGLIA et al., 2017; MACEDO, 2018), que trata de discutir e problematizar as políticas de elaboração, discussão e aprovação da BNCC, considera que houve um preponderante e acentuado protagonismo de setores caracterizados como investidores sociais, além da reduzida participação organizada de educadores/as e universidades, o que poderá implicar em riscos e perigo, em meio aos processos de negação e/ou alienação quanto ao documento. Porque de nada adianta a implantação de normas orientadoras/reguladoras da educação se quem as aplica não está engajado/a no mesmo processo, não é sujeito/a na situação.

Larrosa-Bondía (2002) trata do par experiência sentido, ao afirmar que algo só nos toca quando algo nos acontece, e que tudo aquilo que nos pertence, inevitavelmente foi por nós vivenciado, experienciado. De tal forma que resta saber, em que medida a BNCC toca (porque atinge) a comunidade educativa brasileira, tão carente e precária em muitos lugares, mas também potente, rica, criativa, autêntica e autônoma em outros?

Daí a importância de se ouvir os/as diferentes sujeitos, ficar atento aos acontecimentos, diante das mil e uma maneiras de se reinventar o dito e o não dito, o feito e a história. Sem se esquecer de que os/as fracos/as usam de tática, mesmo que manhosa artimanha de se fazer valer, enquanto os/as fortes usam estratégias (CERTEAU, 1994). Nas relações há sempre quem manda e quem obedece, quase que numa relação de destinatário/a e remetente. Afinal, a BNCC seria tática ou estratégia? Endereçada a quem? A quem receber ou a quem obedecer?

Para Certeau (2014), o que nos move é o que nos afeta, nos desorganiza, convocando novos modos de expressão. Não se pode desprezar as potencialidades e capacidades do ser humano comum, e aqui nos referimos muito especificamente ao/à professor/a, ao/à estudante, a todos/as os/as atores/atrizes da rede social e política da Educação escolar no Brasil. Porque enquanto ser humano comum e à luz das leis impostas, esses/as atores/atrizes fazem a diferença, justamente porque sobrevivem, tocam e são tocados/as, transformam e dão sentido ao fazer e à realidade. A toda essa capacidade de operar é que Certeau nomeia de "usos". Por isso, é necessário ver o visível e o invisível, o audível e o inaudível, o palpável e o impalpável, para só assim sermos capazes de reposicionar nossas operações e entendimentos, abertos e disponíveis para as mudanças em curso. Seria essa a predisposição necessária para a implementação da $\mathrm{BNCC}$ junto à rede de ensino brasileira.

Observa-se que esta apresenta um texto de valorização do caráter salvacionista, com vínculo imediato entre a educação e o desenvolvimento econômico, como se todos os problemas sociais brasileiros fossem resolvidos com a promessa de uma educação pautada em aprendizagens essenciais, padrões uniformizados de saberes e comportamentos, como se os/as profissionais das escolas não soubessem o que fazer. Vale lembrar que as orientações para o currículo não advêm só de normativas em documentos legais, mas de contribuições dos livros didáticos, literatura educacional, processos de formação inicial e continuada de professores/as, projetos e parcerias com instituições e comunidade, avaliações, dentre outras.

Nesse sentido, a BNCC peca duplamente, pela fragmentação apresentada por excluir o Ensino Médio, e modalidades de ensino, e pela restrição conferida à ênfase pedagógica centrada na aprendizagem. Essa concepção e política de forte centralização e protagonismo do governo federal não contribui para o estabelecimento de políticas 
pautadas em relações de efetiva cooperação e colaboração entre os mais diferentes entes envolvidos na educação (órgãos federativos, sistemas de ensino, instituições, profissionais e estudantes).

Há uma tradição educacional brasileira consolidada, a qual não é possível desconsiderar. De tal forma que seria pretensão que todas as escolas seguissem cega e obedientemente as mesmas orientações pedagógicas e determinações educacionais, porque não há metas de aprendizagem que possam garantir a sua exequibilidade e eficácia. Aliás, em meio às oportunidades, mais se acentuam as diferenças. Daí o princípio da solidariedade, da fraternidade, da cooperação e ajuda mútua entre as pessoas, grupos de pessoas e instituições para a promoção e efetivação de uma educação que, verdadeiramente, seja potente e capaz de transformar; que crie a unidade na diferença, como afirma o educador brasileiro Paulo Freire $(1987 ; 2008)$.

Parafraseando Boaventura de Sousa Santos (2002), toda cultura é parcial, e toda apreensão de um real qualquer será também parcial. Nessa perspectiva, o que a BNCC do ensino de Arte na educação infantil e ensino fundamental tem a dizer sobre o que será comum para todas as crianças, tendo em vista a riqueza cultural brasileira e suas especificidades?

\section{O ENSINO DE ARTE NA EdUCAÇÃO INFANTIL E ENSINO FUNDAMENTAL NO CONTEXTO DA BNCC}

A Educação Infantil tem um histórico de cerca de vinte anos. Inicialmente, a oferta de ensino no Brasil se restringia aos cursos primários, com duração de quatro anos, expandindo-se para o ensino fundamental de oito anos. E só depois, na década de 1980, com as novas demandas sociais, principalmente a inserção das mulheres no mercado de trabalho e os impactos na vida organizacional das famílias, é que o atendimento às crianças foi ampliado, do assistencialismo à sistematização do educar e do cuidar (ações complementares e indissociáveis) em crianças de tenra idade. Em razão das novas configurações familiares, dos diferentes papéis entre homens e mulheres, do rompimento de paradigmas e das mudanças sociais, bebês passaram a frequentar as escolas. De tal forma que sistematizar esse ensino foi uma urgência.

A BNCC veio contribuir para essa questão, no sentido de que reconhece e normatiza o lugar dessa(s) criança(s) na escola brasileira. Com base na ideia de que os direitos fundamentais de aprendizagem e desenvolvimento na Educação Infantil são pautados na convivência, no brincar, na participação, exploração, expressão e constituição de identidade, estabelecendo para a Educação Infantil dois eixos estruturantes, que são as interações e as brincadeiras, com cinco campos de experiências (BRASIL, 2018).

O documento estabeleceu para a Educação Infantil (bebês: zero a 1 ano e 6 meses; crianças bem pequenas: 1 ano e 7 meses a 3 anos e 11 meses; crianças pequenas: 4 anos a 5 anos e 11 meses) eixos estruturantes (interações e brincadeiras) organizados em 5 campos de experiências, que são: estética, expressão, estesia, fruição, reflexão (BRASIL, 2018).

Desse modo, as crianças da Educação Infantil, convivendo com outras crianças e adultos, ampliam o conhecimento de si e do outro; brincando com diferentes pessoas, de diversos modos e em diferentes tempos e lugares, ampliam conhecimentos e experiências; participando com outras crianças e adultos da esfera de escolha e decisão de atividades e brincadeiras, desenvolvem diferentes linguagens e elaboram conhecimentos; explorando movimentos, gestos, sons, formas, texturas, cores, palavras, 
emoções etc., na escola e fora dela, ampliam conhecimentos em diversas modalidades (arte, escrita, ciência, tecnologia); expressando-se como sujeitos dialógicos, criativos e sensíveis, ampliam as experiências e descobertas; conhecendo-se, constroem suas identidades pessoal, social e cultural. Enfim, é na interatividade com outras crianças e adultos em diferentes tempos e lugares que as aprendizagens e o desenvolvimento acontecerão (BRASIL, 2018).

Já para o Ensino Fundamental, no contexto da Educação Básica, o componente curricular Arte está centrado nas linguagens das Artes Visuais, Dança, Música e Teatro (BRASIL, 2018).

Essas linguagens articulam saberes referentes a produtos e fenômenos artísticos e envolvem as práticas de criar, ler, produzir, construir, exteriorizar e refletir sobre formas artísticas. A sensibilidade, a intuição, o pensamento, as emoções e as subjetividades se manifestam como formas de expressão no processo de aprendizagem em Arte (BRASIL, 2018, p. 193).

Estas se organizam nas seguintes dimensões: criação, crítica, estesia, expressão, fruição, reflexão, ou seja, arte como conhecimento, como processo de expressão, como forma de ler o mundo, como meio de transformação crítica da realidade, como processo criador (BRASIL, 2018). Assim, a BNCC reitera a necessidade do fim da polivalência na formação docente, bem como no ensino de Arte na escola, gerando-se a necessidade de contratação de professor/a por área e não professor/a de arte (um problema e desafio).

Nessa perspectiva, considera-se como Arte não somente o que é legitimado como tal, mas também, os modos particulares de sentir, lidar e externalizar os sentimentos em contato com a pintura, a escultura, os sons, dentre outros. Esta também se constitui como os significados que atribuímos às diferentes linguagens artísticas, com base no uso dos diferentes sentidos.

\section{COMPARTILHANDO EXPERIÊNCIAS EM ARTE}

Todo sujeito é histórico, social e cultural, com direito à equidade, diversidade, inclusão e aprendizagem, de modo a conviver, brincar, participar, explorar, expressar e conhecer-se. Nessa perspectiva são inúmeras as experiências em Arte, envolvendo as mais diferentes linguagens e possibilidades de interação. Se a pergunta é: O que é Arte? São muitas as respostas, dentre elas, a revelação do simulacro no teatro, a contestação do belo e o desfacelamento das formas nas artes visuais, a escuta atenta, a improvisação e o uso de novas mídias e tecnologias na música, o som, o gesto e o movimento na dança. Enfim, em tempos de interatividade, vivemos um verdadeiro hibridismo artístico, no qual as artes dialogam a ponto de não mais sabermos se determinada obra é cênica ou visual, por exemplo.

Há experiências bem sucedidas e outras não, mas onde se aprende a ser professor/a artista? Aquele/a que compõe com o outro, com a brincadeira, com o jogo da criação, que ensina "no limite do risco", que faz pedagogia plástica e constrói currículos dançantes? Conhecer as competências do ensino de Arte proposto na BNCC e fazer uso das diferentes linguagens é o suficiente? Que projeto pedagógico e curricular poderá ser útil à formação docente? Essas são perguntas que não serão respondidas completamente neste artigo, mas é necessário que algumas pistas sobre o que entendemos por ensino de Arte sejam apresentadas. 
Em 2013, durante cinco meses, vivenciou-se uma experiência ímpar em Maputo, Moçambique, envolvendo música, teatro e literatura. Em uma única sala, o conto "Formiga Juju na cidade das papaias" (PEREIRA, 2011), de Cristiane Pereira e ilustração de Walter Zand, foi trabalhado com oitenta e cinco crianças, de nove a doze anos, fluentes em sete línguas diferentes, tendo o Português como língua oficial. Foi possível fazer e aprender Arte? Mais que isso, numa única palavra: Maravilhoso! (MARTINS; GONÇALVES JUNIOR, 2016).

Uma das autoras deste artigo participou dessa experiência como estudante do Programa de Doutorado Sanduiche no Exterior (PDSE), pela Universidade Federal de São Carlos (UFSCar), bolsista CAPES (Coordenadoria de Aperfeiçoamento de Pessoal do Ensino Superior), e da Universidade Pedagógica de Moçambique. A vivência fez com que se deparasse com o que é diversidade ${ }^{6}$. Evidenciamos que, para redimensionar o termo e seu significado, somente o trabalho em comunidade possibilitou (re)significar nossas experiências e compreensões.

De início a experiência se consistiu em assistir (observar) as aulas de música em uma escola pública, as quais eram ministradas por três professores/as de português (duas mulheres e um homem). Chão batido, carteiras para duas pessoas, lousa, giz e um manual de música (livro didático): escrita notacional, canções portuguesas e muitos exercícios musicais. Tudo dava ares de falta de significado e compreensão, até que a escola recebeu um baú cheio de livros e, a partir desse dia, tudo tomou outra feição: fezse a leitura de dois livros, "Pássaro Azul" e "Formiga Juju", e este último foi aplaudido pelas crianças, sendo que muitas não liam/falavam/escreviam/compreendiam a língua portuguesa.

Ao longo de cinco meses de convivência semanal, o conto "Formiga Juju na cidade das papaias" saiu das linhas do papel, fez-se vida e realidade em meio a narrativas, encenação de personagens, dramatizações, percussão corporal, dança, música, brincadeiras, apresentações e viagens de apresentação. Pela primeira vez, as oitenta e cinco crianças saíram da escola para se apresentarem em outros lugares e, pela primeira vez também, ganharam lanche do diretor: uma garrafa de suco e um pão com geleia. Não há como não se emocionar... Por tudo isso e muito mais, ensinar arte é isto: dar significado às experiências.

Por essas e outras situações, vale apostar na escola, espaço e tempo de gestação de inventividades, instituição potente capaz de transformar cultural, educacional, política e eticamente; escola como espaço educativo-social da condição humana, mesmo em uma sociedade marcada pela lógica capitalista que, recorrentemente, questiona se a arte é necessária.

\section{LIMITES E POTENCIAL DA BNCC}

A BNCC emerge no cenário atual da educação brasileira como promessa de contribuição fundamental para compor, com os esforços já empreendidos nos últimos anos por estados e municípios, na construção de suas orientações curriculares. Sua implementação só se concretizará por meio de inúmeras ações, dentre a formação de professores, a produção de materiais pedagógicos e a força tarefa com vistas à sua implementação dos estados e municípios brasileiros (nesse sentido, Minas Gerais já se adiantou).

\footnotetext{
${ }^{6}$ Destacamos sua condição de estrangeira, branca, mulher, casada há trinta anos, mãe de três filhos/as, professora no Brasil em uma escola de música e em uma universidade.
} 
Mas por quê? Porque não há possibilidade de implementação da BNCC sem o necessário zelo pela garantia das condições materiais de trabalho, de formação inicial de professores/as (com base em ensino, extensão e pesquisa) e de formação continuada, orientada por políticas de desenvolvimento profissional, que incluam plano de carreira, valorização e remuneração de docentes, além da necessária e fundamental autonomia de decisão e construção de propostas curriculares mediadas pelos projetos de ensino e práticas pedagógicas das inúmeras escolas e educadores/as.

Daí a necessária tetralogia BNCC/Currículo/Projeto Político Pedagógico/Plano de ensino e de aula. Portanto, a BNCC (mesmo que o termo não seja explícito em sua significação, mas considerados os tantos sujeitos de sua aplicação) é compreendida como referência e não como currículo. Ou seja, a Base é o ponto final do percurso, que é o currículo (o quê, porquê, quando e como ensinar), dependendo de quem o realiza in loco, de modo a ser capaz de ação-reflexão-ação, ou seja, a práxis enquanto atividade de cada pessoa envolvida na promoção de uma educação escolar brasileira transformadora e libertadora.

Caminhamos, mas ainda há muito a caminhar. Da escola para poucos passamos à escola para alguns. Na esperança renovada enquanto necessidade ontológica (FREIRE, 2008), aguardamos a educação escolar brasileira como escola de muitos. Nessa tarefa, somos trabalhadores/as!

Entretanto, é preciso reconhecer a existência das desigualdades, cuja problemática não há como ocultar, e cujo cerne da questão reside em investimentos diferenciados para a carreira do/a professor/a, para as condições de trabalho nas escolas, as vidas das famílias, as condições de estudo dos/as estudantes, a infraestrutura familiar, as oportunidades que existem fartamente para uns em detrimento de nada ou quase nada para outros. Enfim, em um mundo de tamanha desigualdade de oportunidade e condições, não há como implementar políticas educacionais de desenvolvimento educacional sem a transformação da base. Mas o que é a base? Trata-se de uma formação sólida, responsável, comprometida, apaixonada e criativa dos/as profissionais da educação (e eles e elas estão aí e são muitos!), é a escola com investimento e manutenção em sua infraestrutura, é a política de efetivação de cargos e planos de carreira e até mesmo de aposentadoria e afastamento para aqueles/as que já estão desesperançados/as. Essa é a base!

\section{REFERÊNCIAS}

AGUIAR, M. Â. S. Relato da resistência à instituição da BNCC pelo Conselho Nacional de Educação mediante pedido de vista e declarações de votos. In: AGUIAR, M. Â. S.; DOURADO, L. F. (Orgs.). A BNCC na contramão do PNE 2014-2024: avaliação e perspectivas. Recife: ANPAE, 2018.

BRASIL. Base Nacional Comum Curricular (BNCC). Versão homologada. Brasília: MEC/CONSED/UNDIME, 2018.

BRASIL. Lei no 13.005, de 25 de junho de 2014. Aprova o Plano Nacional de Educação - PNE e dá outras providências. Brasília: Casa Civil, 2014.

BRASIL. Lei n. ${ }^{\circ}$ 12.796, de 4 de abril de 2013. Altera a Lei ${ }^{\circ}$ 9.394, de 20 de dezembro de 1996, que estabelece as diretrizes e bases da educação nacional, para dispor sobre a formação dos profissionais da educação. Brasília: Casa Civil, 2013a.

BRASIL. Diretrizes Curriculares Nacionais para a Educação Básica. Brasília: MEC, SEB, DICEI, 2013b. 
BRASIL. Diretrizes Curriculares Nacionais para a Educação Infantil. Brasília: MEC/SEB, 2010.

BRASIL. Emenda Constitucional n. ${ }^{\circ}$ 59, de 11 de novembro de 2009. Brasília: Casa Civil, 2009.

BRASIL. Lei n. 010172, de 9 de janeiro de 2001. Aprova o Plano Nacional de Educação. Brasília: Casa Civil, 2001.

BRASIL. Referencial Curricular Nacional para a Educação Infantil. Brasília: MEC/SEF, 1998. (Volume 1).

BRASIL. Parâmetros Curriculares Nacionais: introdução aos Parâmetros Curriculares Nacionais. Brasília: MEC/SEF, 1997.

BRASIL. Lei n. ${ }^{\circ}$ 9394, de 20 de dezembro de 1996. Estabelece as diretrizes e bases da educacional nacional. Brasília: Casa Civil, 1996.

BRASIL. Constituição da República Federativa do Brasil. Brasília: Casa Civil, 1988.

CERTEAU, M. A invenção do cotidiano I: as artes do fazer. 22. ed. Petrópolis: Vozes, 2014.

FREIRE, P. Pedagogia da esperança: um reencontro com a pedagogia do oprimido. 15. ed. Rio de Janeiro: Paz e Terra, 2008.

FREIRE, P. Pedagogia do oprimido. 17. ed. São Paulo: Paz e Terra, 1987.

LARROSA-BONDÍA, J. Notas sobre a experiência e o saber de experiência. Tradução de João Wanderley Geraldi. Revista Brasileira de Educação, n. 19, p. 20-28, 2002.

MACEDO, E. "A base é a base”. E o currículo o que é? In: AGUIAR, M. Â. S.; DOURADO, L. F. (Orgs.). A BNCC na contramão do PNE 2014-2024: avaliação e perspectivas. Recife: ANPAE, 2018. p. 31-36.

MARSIGLIA, A. C. G.; PINA, L. D.; MACHADO, V. O.; LIMA, M. A base nacional comum curricular: um novo episódio de esvaziamento da escola no Brasil. Germinal: marxismo e educação em debate, v. 9, n. 1, p. 107-121, abr. 2017.

MARTINS, D. A. F.; GONÇALVES JUNIOR, L. A Formiga Juju na cidade das papaias: música geradora na escola de educação básica de Maputo, Moçambique. In: CONGRESSO IBEROAMERICANO EM INVESTIGAÇÃO QUALITATIVA, 5., 2016, Porto, Portugal. Anais... Porto, Universidade Lusófona do Porto, 2016. p. 1-10.

PEREIRA, C. A formiga Juju na cidade das papaias. Maputo: Conteúdos \& Publicações, 2011.

SANTOS, B. S. Para uma sociologia das ausências e uma sociologia das emergências. Revista Crítica de Ciências Sociais, v. 63, p. 237-280, 2002.

VALLADARES, M. T. R.; GIRARDI, G.; NOVAES, Í. F.; NUNES, F. G. Contexto da construção da primeira e segunda versões da Base Nacional Comum Curricular no componente curricular de Geografia. Giramundo, Rio de Janeiro, v. 3, n. 6, p. 7-18, jul./dez. 2016.

Recebido em: 06 jun. 2019.

Aprovado em: 04 out. 2019. 